\title{
Histological changes in human dental pulp following application of intrusive and extrusive orthodontic forces
}

\author{
Barat A. Ramazanzadeh ${ }^{1)}$, Abbas A. Sahhafian ${ }^{1)}$, Nooshin Mohtasham ${ }^{2)}$, \\ Nadia Hassanzadeh ${ }^{1)}$, Arezoo Jahanbin ${ }^{1)}$ and Mohammad T. Shakeri ${ }^{3)}$ \\ ${ }^{1)}$ Department of Orthodontics, Faculty of Dentistry and Dental School Research Center, \\ Mashhad University of Medical Sciences, Mashhad, Iran \\ ${ }^{2)}$ Department of Oral Pathology, Faculty of Dentistry and Dental School Research Center, \\ Mashhad University of Medical Sciences, Mashhad, Iran \\ ${ }^{3)}$ Department of Community Medicine and Public Health, Mashhad University of Medical Sciences, \\ Mashhad, Iran
}

(Received 9 June and accepted 24 December 2008)

\begin{abstract}
The aim of this study was to compare the effects of orthodontic extrusive and intrusive forces on histological changes of the human dental pulp. In this clinical trial, 52 sound upper first premolars from 26 patients scheduled for extraction for orthodontic reasons were selected. They were divided into 2 groups, based on the time intervals for histological evaluation ( 3 days and 3 weeks). In each group, 10 teeth received orthodontic extrusive forces, 10 teeth underwent intrusive forces, and 6 teeth served as controls. After each period, teeth were extracted and prepared for histological examination under light microscopy and some histological parameters were evaluated. The data were statistically analyzed by Kruskall-Wallis and Mann Whitney tests. Of the parameters evaluated, just vacuolization and disruption of the odontoblastic layer showed statistically significant differences between the control group and both of the experimental groups in each test period $(P<0.05)$. Additionally, there was no significant difference between 3-day and 3-week intervals in each experimental group, except for fibrosis in the extrusive group which significantly increased after
\end{abstract}

Correspondence to Dr. Arezoo Jahanbin, Department of Orthodontics, Faculty of Dentistry and Dental School Research Center, Mashhad University of Medical Sciences, Vakilabad Blvd, Mashhad, Iran

Tel: +98-9151107306

Fax: +98-5118829500

E-mail: Jahanbina@mums.ac.ir
3 weeks of force application $(P=0.001)$. Histological pulp changes following extrusive and intrusive force applications for 3 days and 3 weeks show no difference from each other. (J Oral Sci 51, 109-115, 2009)

Keywords: histology; pulp; extrusive; intrusive.

\section{Introduction}

Blood flowing through the tooth is controlled in a unique environment. The dental pulp is encased with a rigid, noncompliant shell and its survival is dependent on the blood vessels that access the interior of the tooth through the apical foramen. As a consequence of these unusual environmental constraints, changes in pulpal blood flow or vascular tissue pressure can have serious implications for the health of dental pulp (1). Understanding the effects of orthodontic force on the pulp is of particular importance, especially because altered pulpal respiration rate, pulpal obliteration by secondary dentin formation, internal root resorption, and pulpal necrosis have all been associated with orthodontic treatment (2). Numerous studies have demonstrated that orthodontic force application may lead to significant pulpal reactions such as hyperemia, diapedesis, margination of white blood cells, stasis, vacuole formation in the odontoblastic layer, cyst formation, and hemorrhage (3-7). Some investigators showed that main pulp changes following application of intrusive forces included vacuolization of the pulp tissue, circulatory 
disturbances, congestion, hemorrhage, and fibrohyalinosis (8-10).

In addition, Konno et al. showed that histological changes during molar intrusion with the skeletal anchorage system in dogs are reversible (11). In 1996, Brodin et al. concluded that orthodontic intrusion of human lateral incisors with a $2 \mathrm{~N}$ force evoked a temporary reduction in the pulpal blood flow, whereas extrusion had no effect on the pulpal blood flow (12). In this regard Grünheid et al. showed that forceinduced movement of molar teeth in rats may lead to extensive, however temporary, trauma of the pulpal tissues, which react with early wound-healing events, such as macrophage invasion, cell proliferation and angiogenesis (13).

The purpose of this study was to investigate and compare the response of the human dental pulp tissue to extrusive and intrusive force applications for 3 days and 3 weeks. The results of this study could help orthodontists to understand whether the pathology of the pulp, which might occur in response to force-induced therapeutic tooth movement, is transient or permanent and could help them in determining long-term prognosis of the teeth.

\section{Materials and Methods}

Tooth specimens

In this clinical trial, 52 maxillary first premolars from 26 patients (16 females and 10 males) between the ages $14-24$ (mean $=16.8$ years, $\mathrm{SD}=3.2$ ) scheduled for extraction before the beginning of orthodontic treatment were used. Clinical and radiographic evaluations determined that the teeth were fully developed with mature apices, non carious, non restored, and showed no periodontal involvement. Ethical approval was given by the Research Ethics Committee of Mashhad University of Medical Sciences on condition that only patients who wished to

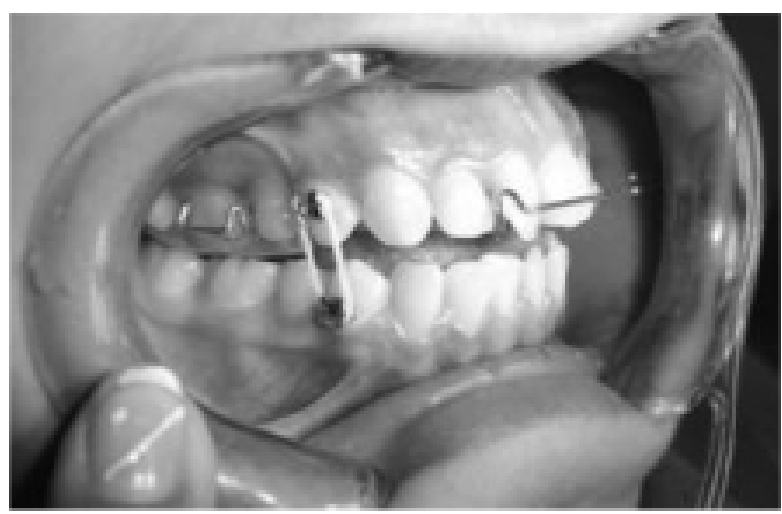

Fig. 1 Extrusive force application by means of elastics on the brackets. participate with informed consent were included in this study. If the patients were less than 18 years old, informed consents were signed by their parents.

In the present study, time periods for histological evaluation of the pulp were set at 3 days and 3 weeks (14). In the first step, the patients were divided randomly into two equal groups of 13 patients. In each group, extrusive force was applied to three maxillary premolars of 3 patients, while the contra lateral premolars were used as untreated intra-patient controls. Also, in each group, intrusive force was applied to three maxillary premolars of 3 other patients, while the contra lateral premolars were used as controls, and for the residual seven patients, maxillary first premolars were loaded by extrusive force and the opposite teeth were loaded by the intrusive force. The side for each intervention was chosen at random. In all, twenty teeth were intruded, twenty teeth were extruded, and 12 teeth were considered as controls.

\section{Force application to the teeth}

In order to avoid traumatic occlusion and to provide space for extrusive movement, a removable orthodontic appliance with bite plates was used in this study. After appliance delivery and adjustment of it, the posterior bite plate was removed from occlusal surfaces of the extrusive teeth and their contra lateral controls. The patients were told to use the removable appliance full time and not to remove it even during meals.

Next, the 0.018 inch standard edgewise premolar brackets (Dentaurum, Dentaurum company, Ispringen, Germany) were direct bonded by a self-cured composite resin (Master Dent, Prime Dental company, Medellin, Colombia, USA) to the buccal surfaces of upper premolars (in both sides) as well as lower premolars in sides loaded by extrusive forces (Fig. 1).

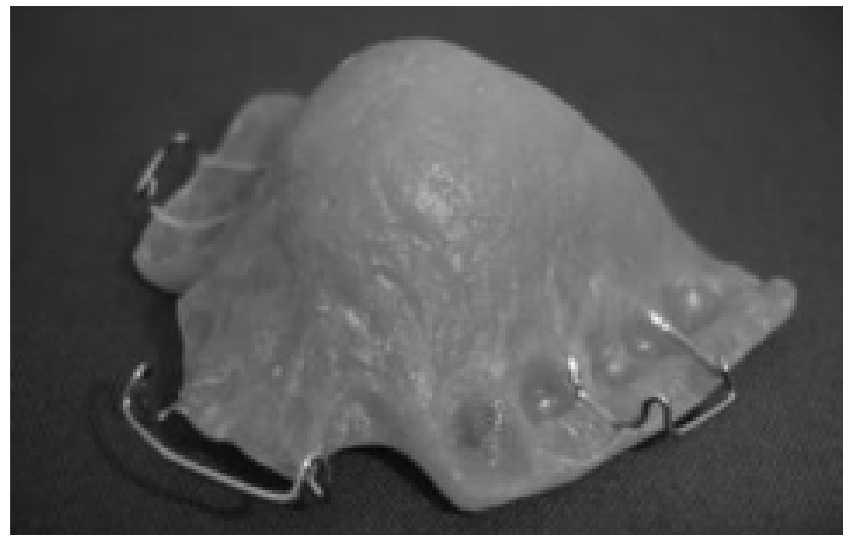

Fig. 2 Intrusive force application by means of a NiTi coil spring inserted into the removable appliance. 
The teeth were extruded by means of $1 / 4$ inch light elastics (Dentaurum, Dentaurum company, Ispringen, Germany), which were hooked from upper premolar brackets to the lower premolar brackets and approximately $75 \mathrm{~g}$ force was applied to the teeth. The patients were told to change the elastics every 24 hours and immediately in case of breakage.

In this study, tooth intrusion was carried out by means of a NiTi open coil spring $(0.010 \times 0.030$ inch, Orthotechnology, USA) that was inserted into the removable appliance (Fig. 2). The intrusive force on the upper premolars was approximately $25 \pm 5 \mathrm{~g}$ and it was applied in right angle to the middle point of the occlusal surface. By considering force degradation of elastics and coils and in order to counteract with force decay and to apply forces in their optimum ranges, we used $75 \mathrm{~g}$ force for extrusive and $25 \mathrm{~g}$ force for intrusive movements. Stripping was done by means of one-side abrasive strips ( $4 \mathrm{~mm}$ width, Medium size particles, Dentaurum, Dentaurum company) to remove contact points between the intrusive loaded upper premolars and adjacent teeth as well as their controls. This was also done for extrusive applied teeth and their controls in order to create similar situations.

\section{Tooth extraction and preparation of microscopic sections}

Extractions were made after test periods of 3 days and 3 weeks. All the teeth were extracted by an expert dentist with minimum trauma. After extraction, the tip of each root was cut with a bur to facilitate fixation. Immediately after removal, the teeth were fixed in 10\% formalin for one week and then immersed in a decalcifying solution including 5 $\mathrm{ml}$ pure nitric acid, $5 \mathrm{ml}$ pure formalin, and $90 \mathrm{ml} 95 \%$ alcohol for 7-10 days. Then the specimens were decalcified and embedded in paraffin (15). Serial sections $(4-5 \mu \mathrm{m}$ thick) were cut longitudinally from each tooth and stained with hematoxylin and eosin dye.

\section{Histological evaluation}

Serial sections of each tooth were examined by an expert pathologist by means of a light microscope (Leica, HAD, Model SSC- DC58AP, Exwave, USA) including a colored digital camera (Sony, Tokyo, Japan). The pathologist was blind regarding the specimens. The histological changes that were assessed in this study are as follows (15):

1) Degree of inflammation was scored by counting inflammatory cells:

None $=0-1$ cell per high-power field, mild inflammation $=2-5$ cells per high-power field, moderate inflammation $=6-15$ cells per high-power field, severe inflammation $=$ more than 15 cells per high-power field.

2) Acute or chronic inflammation of the pulp.

3) Mild to severe fibrotic tissue formation.

4) None, partial, or complete necrosis of the pulp.

5) Mild to severe disruption of odontoblastic layer.

6) None or some odontoblast aspiration into the dentin tubules.

7) None or some formation of reparative dentin.

8) None, one, or several pulp stones in the pulp tissue.

9) Mild to severe dilatation in vessels diameter.

10) Mild to severe vacuole formation in the odontoblastic layer.

11) None or some resorption of dentin or cementum.

\section{Statistical analysis}

After data collection, they were analyzed using SPSS software (version 10). The data was analyzed by KruskalWallis and Mann Whitney tests, with $P<0.05$ used to indicate significant difference.

\section{Findings at 3 days}

\section{Results}

According to Table 1, there were significant differences between extrusive, intrusive, and control groups for disruption as well as vacuolization of the odontoblastic layer 3 days after force application $(P<0.05)$ (Fig. 3). The Mann Whitney test showed, for odontoblastic layer disruption there were significant differences between extrusive group $(P=0.029)$ and intrusive $(P=0.041)$ groups with the control group but the differences between extrusive and intrusive groups were not significant. Similarly, for vacuolization of the odontoblastic layer, there were significant differences between extrusive $(P=0.004)$ and intrusive $(P=0.003)$ groups with the control group but the differences between extrusive and intrusive groups were not significant (data not shown).

Table 2 shows that the degree of inflammation and pulp vessels dilatation after 3 days were not significantly different among intrusive, extrusive and control groups. In addition, there was no tooth showing reparative dentin formation, pulp necrosis and resorption of dentin or cementum, but two pulps in the extrusive group and 1 pulp in the intrusive group demonstrated odontoblast aspiration, while no tooth in the control group showed this finding. In addition, only 3 teeth in the extrusive group showed chronic inflammation, while other teeth did not show it in the intrusive and the control groups (data not shown).

\section{Findings at 3 weeks}

Table 3 shows the difference among extrusive, intrusive and control groups for disruption, and vacuolization in 


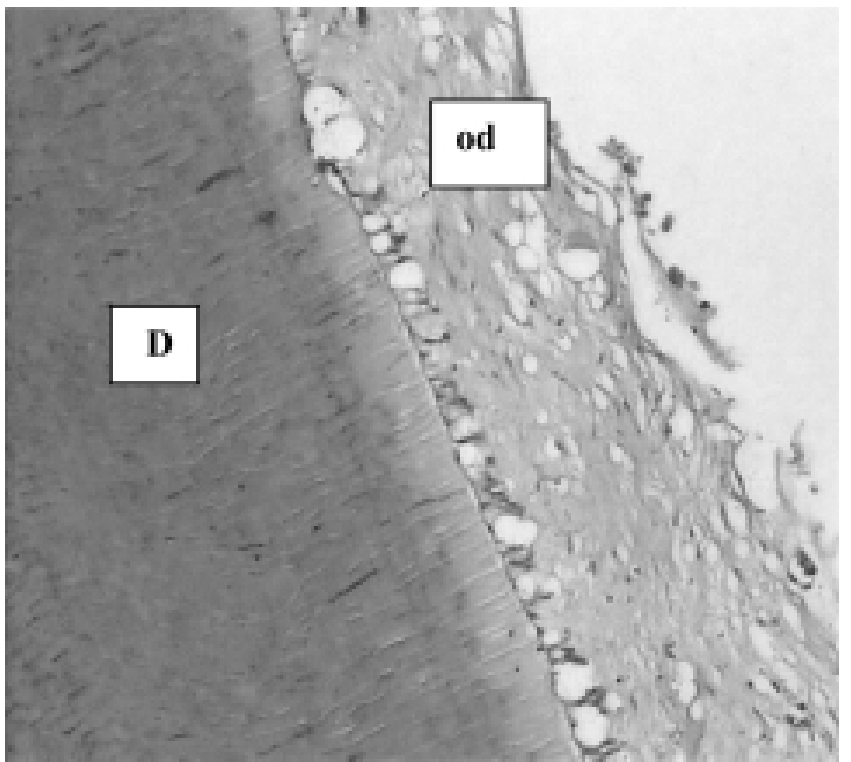

Fig. 3 Vacuolization in odontoblastic layer of a specimen from the 3 days intrusive group. D: Dentin, od: odontoblastic layer, H-E staining $\times 100$. odontoblastic layer, and fibrous tissue formation was statistically significant after 3 weeks $(P<0.05)$ (Figs. 4 and 5). Moreover, the Mann Whitney test showed the odontoblastic layer underwent disruption and vacuolization, and there were significant differences between the extrusive with control groups $(P=0.001$ and $P=0.004$, respectively) and the intrusive with the control group $(P=0.011$ and $P$ $=0.011$, respectively), but there were no significant differences between extrusive and intrusive groups (data not shown).

According to the Mann Whitney test, fibrous tissue formation after 3 weeks had statistically significant difference just between controls and the extrusive group $(P=0.001)$, but there was no significant difference between controls and the intrusive group as well as extrusive and intrusive groups for this matter (data not shown).

Table 4 showed that the degree of inflammation and pulp vessel dilatation after 3 weeks were not different significantly among extrusive, intrusive and control groups $(P>0.05)$. According to table 5, there were no significant

Table 1 Frequency distribution for disruption and vacuolization in odontoblastic layer and fibrous tissue formation following application of intrusive and extrusive forces for 3 days

\begin{tabular}{|c|c|c|c|c|c|c|c|c|c|}
\hline \multirow[t]{2}{*}{ Degree } & \multicolumn{3}{|c|}{ Disruption } & \multicolumn{3}{|c|}{ Vacuolization } & \multicolumn{3}{|c|}{ Fibrous tissue formation } \\
\hline & Control & Extrusive & Intrusive & Control & Extrusive & Intrusive & Control & Extrusive & Intrusive \\
\hline None & $3(50 \%)$ & $2(10 \%)$ & $2(20 \%)$ & $3(50 \%)$ & $0(0.0 \%)$ & $0(0.0 \%)$ & $5(83.3 \%)$ & $10(100 \%)$ & $9(90 \%)$ \\
\hline Mild & $3(50 \%)$ & $1(10 \%)$ & $2(20 \%)$ & $2(33.3 \%)$ & $1(10 \%)$ & $1(10 \%)$ & $1(16.7 \%)$ & $0(0 \%)$ & $1(10 \%)$ \\
\hline Moderate & $0(0 \%)$ & $3(30 \%)$ & $5(50 \%)$ & $1(16.7 \%)$ & $5(50 \%)$ & $9(90 \%)$ & $0(0 \%)$ & $0(0 \%)$ & $0(0 \%)$ \\
\hline Severe & $0(0 \%)$ & $4(40 \%)$ & $1(10 \%)$ & $0(0.0 \%)$ & $4(40 \%)$ & $0(0.0 \%)$ & $0(0 \%)$ & $0(0 \%)$ & $0(0 \%)$ \\
\hline $\begin{array}{c}\text { Total } \\
\text { Kruskal-Wallis test }\end{array}$ & $6(100 \%)$ & $\begin{array}{l}10(100 \%) \\
P=0.045\end{array}$ & $10(100 \%)$ & $6(100 \%)$ & $\begin{array}{l}10(100 \%) \\
P=0.002\end{array}$ & $10(100 \%$ & $6(100 \%)$ & $\begin{array}{l}10(100 \%) \\
P=0.466\end{array}$ & $10(100 \%$ \\
\hline
\end{tabular}

Table 2 Frequency distribution for degree of inflammation and pulp vessel dilatation following application of intrusive and extrusive forces for 3 days

\begin{tabular}{|c|c|c|c|c|c|c|}
\hline \multirow[t]{2}{*}{ Degree } & \multicolumn{3}{|c|}{ Degree of inflammation } & \multicolumn{3}{|c|}{ Pulp vessels dilatation } \\
\hline & Control & Extrusive & Intrusive & Control & Extrusive & Intrusive \\
\hline None & $6(100 \%)$ & $7(70 \%)$ & $10(100 \%)$ & $3(50 \%)$ & $2(20 \%)$ & $4(40 \%)$ \\
\hline Mild & $0(0 \%)$ & $0(0 \%)$ & $0(0 \%)$ & $1(16.7 \%)$ & $4(40 \%)$ & $2(20 \%)$ \\
\hline Moderate & $0(0 \%)$ & $3(30 \%)$ & $0(0 \%)$ & $2(33.3 \%)$ & $20(20 \%)$ & $4(40 \%)$ \\
\hline Severe & $0(0 \%)$ & $0(0 \%)$ & $0(0 \%)$ & $0(0 \%)$ & $2(20 \%)$ & $0(0 \%)$ \\
\hline $\begin{array}{c}\text { Total } \\
\text { Kruskal-Wallis test }\end{array}$ & $6(100 \%)$ & $\begin{array}{l}10(100 \%) \\
P=0.074\end{array}$ & $10(100 \%)$ & $6(100 \%)$ & $\begin{array}{l}10(100 \%) \\
P=0.543\end{array}$ & $10(100 \%$ \\
\hline
\end{tabular}

Table 3 Frequency distribution for disruption, and vacuolization in odontoblastic layer as well as fibrous tissue formation following application of intrusive and extrusive forces for 3 weeks

\begin{tabular}{|c|c|c|c|c|c|c|c|c|c|}
\hline \multirow[t]{2}{*}{ Degree } & \multicolumn{3}{|c|}{ Disruption } & \multicolumn{3}{|c|}{ Vacuolization } & \multicolumn{3}{|c|}{ Fibrous tissue formation } \\
\hline & Control & Extrusive & Intrusive & Control & Extrusive & Intrusive & Control & Extrusive & Intrusive \\
\hline None & $6(100 \%)$ & $1(10 \%)$ & $3(30 \%)$ & $6(100 \%)$ & $2(20 \%)$ & $3(30 \%)$ & $5(83.3 \%)$ & $2(20 \%)$ & $6(60 \%)$ \\
\hline Mild & $0(0 \%)$ & $0(0 \%)$ & $0(0 \%)$ & $0(0.0 \%)$ & $0(0.0 \%)$ & $0(0.0 \%)$ & $1(16.7)$ & $2(20 \%)$ & $1(10 \%)$ \\
\hline Moderate & $0(0 \%)$ & $8(80 \%)$ & $5(50 \%)$ & $0(0.0 \%)$ & $6(60 \%)$ & $5(50 \%)$ & $0(0.0 \%)$ & $3(30 \%)$ & $2(20 \%)$ \\
\hline Severe & $0(0 \%)$ & $1(10 \%)$ & $2(20 \%)$ & $0(0.0 \%)$ & $2(20 \%)$ & $2(20 \%)$ & $0(0.0 \%)$ & $3(30 \%)$ & $1(10 \%)$ \\
\hline $\begin{array}{c}\text { Total } \\
\text { Kruskal-Wallis test }\end{array}$ & $6(100 \%)$ & $\begin{array}{l}10(100 \%) \\
P=0.005\end{array}$ & $10(100 \%)$ & $6(100 \%)$ & $\begin{array}{l}10(100 \%) \\
P=0.011\end{array}$ & $10(100 \%)$ & $6(100 \%)$ & $\begin{array}{l}10(100 \%) \\
P=0.028\end{array}$ & $10(100 \%$ \\
\hline
\end{tabular}


differences among extrusive, intrusive and control groups for pulp stone formation 3 days and 3 weeks after force application $(P>0.05)$. Additionally, after 3 weeks there were no teeth showing reparative dentin formation except for one tooth from the control group. However, resorption of dentin or cementum did not show in all the groups in this time interval. This study showed only 1 pulp in the intrusive group demonstrated odontoblast aspiration and one pulp in the extrusive group showed incomplete necrosis; other teeth did not show these findings. Also, in this time interval, only 3 teeth in the extrusive group and 1 tooth in

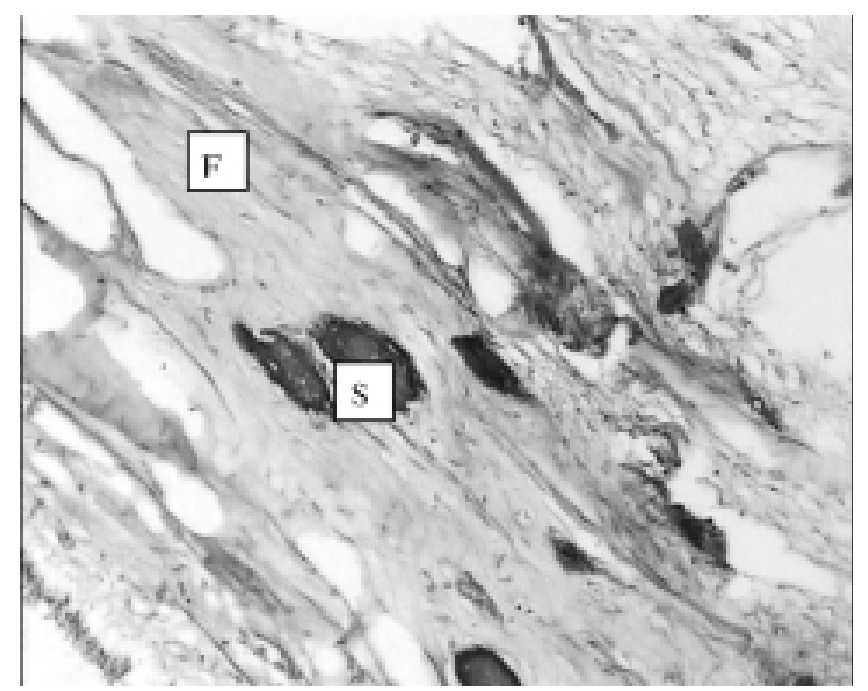

Fig. 4 Fibrous tissue formation increase in a specimen from 3 weeks extrusive group. s: pulp stone, F: fibrous tissue, $\mathrm{H}-\mathrm{E}$ staining $\times 100$. the intrusive group showed chronic inflammation, while the control group did not show it.

On the other hand in comparing all the variables in the intrusive group, there were no significant differences between 3 days and 3 weeks, but for the extrusive group, fibrous tissue formation had a significant difference between the two time periods (Table 6).

\section{Discussion}

The purpose of this histological study was to investigate the response of human dental pulp tissue to extrusive and

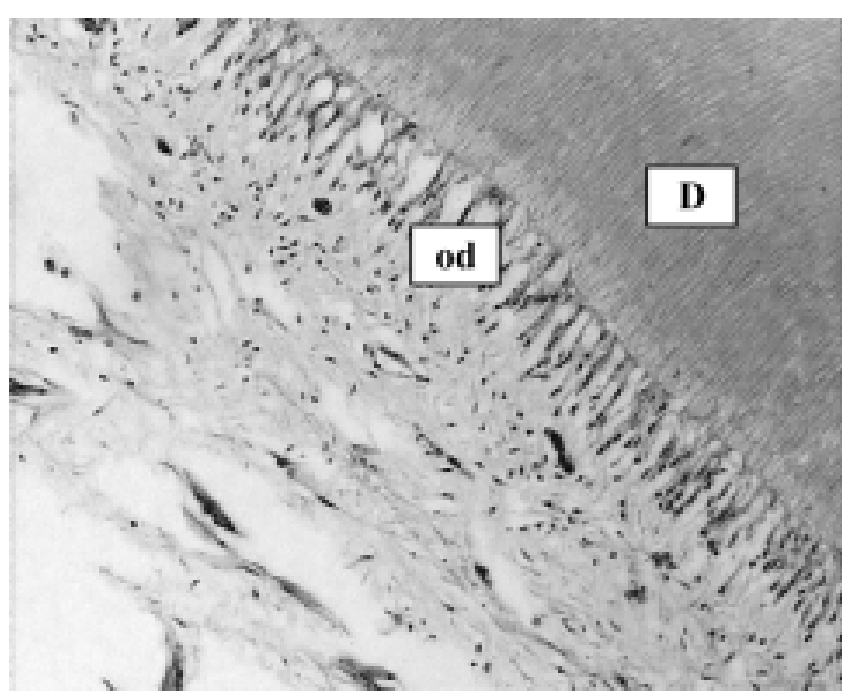

Fig. 5 Odontoblastic layer disruption of a specimen from 3 weeks intrusive group. D: Dentin, od: odontoblastic layer, H-E staining $\times 100$.

Table 4 Frequency distribution for degree of inflammation and pulp vessel dilatation following application of intrusive and extrusive forces for 3 weeks

\begin{tabular}{|c|c|c|c|c|c|c|}
\hline \multirow[t]{2}{*}{ Degree } & \multicolumn{3}{|c|}{ Degree of inflammation } & \multicolumn{3}{|c|}{ Pulp vessel dilatation } \\
\hline & Control & Extrusive & Intrusive & Control & Extrusive & Intrusive \\
\hline None & $6(100 \%)$ & $8(80 \%)$ & $9(90 \%)$ & $6(100 \%)$ & $7(70 \%)$ & $5(50 \%)$ \\
\hline Mild & $0(0 \%)$ & $1(10 \%)$ & $0(0 \%)$ & $0(0 \%)$ & $1(10 \%)$ & $1(10 \%)$ \\
\hline Moderate & $0(0 \%)$ & $0(0 \%)$ & $1(10 \%)$ & $0(0 \%)$ & $0(0 \%)$ & $3(30 \%)$ \\
\hline Severe & $0(0 \%)$ & $1(10 \%)$ & $0(0 \%)$ & $0(0 \%)$ & $2(20 \%)$ & $1(10 \%)$ \\
\hline $\begin{array}{c}\text { Total } \\
\text { Kruskal-Wallis test }\end{array}$ & $6(100 \%)$ & $\begin{array}{l}10(100 \%) \\
P=0.486\end{array}$ & $10(100 \%)$ & $6(100 \%)$ & $\begin{array}{l}10(100 \%) \\
P=0.148\end{array}$ & $10(100 \%$ \\
\hline
\end{tabular}

Table 5 Comparison of pulp stone formation among intrusive, extrusive and control groups after 3 days and 3 weeks

\begin{tabular}{cccccccc}
\hline Pulp stone formation & \multicolumn{3}{c}{ After 3 days } & & \multicolumn{3}{c}{ After 3 weeks } \\
\cline { 2 - 3 } \cline { 6 - 8 } & Control & Extrusive & Intrusive & & Control & Extrusive & Intrusive \\
\hline None & $5(83.3 \%)$ & $8(80 \%)$ & $8(90 \%)$ & & $4(66.6 \%)$ & $8(80 \%)$ & $7(70 \%)$ \\
Single & $0(0 \%)$ & $1(10 \%)$ & $1(0 \%)$ & & $1(16.7 \%)$ & $1(10 \%)$ & $1(10 \%)$ \\
Multiple & $1(16.7 \%)$ & $1(0 \%)$ & $1(10 \%)$ & & $1(16.7 \%)$ & $1(10 \%)$ & $2(20 \%)$ \\
\hline Total & $6(100 \%)$ & $10(100 \%)$ & $10(100 \%)$ & & $6(100 \%)$ & $10(100 \%)$ & $10(100 \%)$ \\
Kruskal-Wallis test & & $P=0.996$ & & & & $P=0.810$ & \\
\hline
\end{tabular}


Table 6 Comparison of fibrous tissue formation of extrusive group after 3 days and 3 weeks

\begin{tabular}{ccc}
\hline Fibrous tissue formation & After 3 days & After 3 weeks \\
\hline None & $10(100 \%)$ & $2(20 \%)$ \\
Mild & $0(0 \%)$ & $2(20 \%)$ \\
Moderate & $0(0 \%)$ & $3(30 \%)$ \\
Severe & $0(0 \%)$ & $3(30 \%)$ \\
Total & $10(100 \%)$ & $10(100 \%)$ \\
\hline Mann-Whitney test & $P=0.001$ & \\
\hline
\end{tabular}

intrusive force applications for 3 days and 3 weeks. The main reason for selecting these time intervals was to compare early with late histological pulp responses. Moreover because it was suspected that signs of inflammation appear gradually due to light forces applied, we began to study pulp changes after 3 days (14). On the other hand, as chronic histological pulp changes need more time to appear; in this study we investigated these changes after 3 weeks. Proffit and Fields considered a range of 35$60 \mathrm{~g}$ and 10-20 $\mathrm{g}$ to be the optimum force magnitudes for extrusion and intrusion, respectively, furthermore Woodside, Berger and Hanson considered 50-100 g as light forces $(15,16)$. For these reasons we chose forces at $75 \mathrm{~g}$ for extrusion and $25 \mathrm{~g}$ for intrusion in present study.

The results indicated the odontoblastic layer disruption and vacuolization following application of extrusive and intrusive forces for 3 days and 3 weeks was significantly more than the control group. However, the lack of significant difference between extrusive and intrusive groups may be due to light forces used in this study. In this regards, Mostafa et al. showed severe odontoblastic degeneration to extrusive forces and related it to compromised blood supply, he showed also large vacuoles in the odontoblastic layer of extrusive group, but Subay et al. did not report vacuolization as a pulp histological finding $(9,17)$. In addition, Stenvic and Mjör reported odontoblastic degeneration and also vacuolization due to intrusive forces (8).

In this present study, one specimen in the control group and one specimen in intrusive group showed mild fibrous tissue formation after 3 days. It is known that the distribution of the collagen fibrils in the pulp may change with age, leading to the appearance of fibrous bundles. These changes also accelerate in response to environmental stimuli, such as caries or attrition of enamel. As we had selected non carious, non restored teeth, we suggest that this change may be due to occlusal trauma (18).

According to the results of this study, although there were no significant differences in fibrous tissue formation between extrusive and intrusive groups with the control group after 3 days, a significant difference was shown between extrusive and control groups after 3 weeks that may be due to the fact that formation of fibrous tissue is a part of the healing process which may take time. Also the lack of significant differences between controls and the intrusive group after 3 weeks may be related to the light forces applied in this study. These findings are similar to Mostafa et al. study and in contrast to Subay et al. investigation $(9,15)$.

In the present study, $10 \%$ of specimens in intrusive group after 3 says and 3 weeks showed odontoblastic aspiration. Some investigators have shown that one of the first visible pulp reactions to external stimulus is the aspiration of odontoblasts $(9,15)$. In Subay et al. study, $22.5 \%$ of specimens showed odontoblastic aspiration (15). Since in our study, odontoblastic aspiration was seen only in one tooth after 3 days (10\% of intrusive cases) and it remained unchanged after 3 weeks (again 10\% of intrusive cases), also it was not seen in control and extrusive groups, we can conclude the odontoblastic aspiration is possibly the result of trauma forceps during tooth extraction. Pulp calcification is a very common finding with an unknown cause. Some investigators believe that pulp calcification is a pathologic process related to different forms of damage; however, others consider this finding as normal (1). Although in this study pulp stones were seen in some specimens of both experiment and control groups after two time intervals, there were no significant differences between extrusive and intrusive groups with controls. Therefore, we can conclude that there is no relationship between force application and pulp stone formation.

In the present study, vascular dilatation, formation of reparative dentin and resorption after 3 days and 3 weeks were not significantly different among extrusive, intrusive and control groups in test periods. The absence of significant differences between experimental groups and controls for vascular dilatation and resorption may be due to relatively light forces used in this study, however; reparative dentin formation begins with an injury to peripheral odontoblastic processes. Since, in this study, reparative dentin formation was not seen in any of the groups, it may be the result of light forces applied in this study. In addition, there is a time interval between tooth injury and beginning of reparative dentin formation because of the proliferation and differentiation of new odontoblasts and this process takes time exceeded our test period (1). Mostafa et al. showed circulatory disturbances as dilated and congested blood vessels, and no formation of reparative dentin after application of 57-48 g extrusive forces (9). Stenvic and Mjor resulted in stasis in the pulp vessels, as judged by the presence of brown pigment from deteriorating erythrocytes 
by application of intrusive forces higher than 150-200 g, furthermore they found cementum and dentin resorption in 60 percent of the experimental teeth(8).

It is known that the first premolars roots are completely formed at 13 to 15 years of age (9). The subjects in this study were between 16-17 years old on average. However the minimum age of the patients was 14 , and at this age, the apical foramen is relatively wide and the forces applied to the maxillary first premolars seem to cause a topographic change in the pulp or prolapse, made possible by the relatively large apical foramen. This prolapse may be responsible for the rupture in the pulp tissue. This conclusion must be viewed as speculative, so further studies are suggested.

On the basis of the results obtained from this study, the following conclusions were drawn:

1. Histological changes caused by orthodontic extrusion are not different after 3 days and 3 weeks, except for fibrous tissue formation that is seen more after 3 weeks.

2 . There was no significant difference between histological changes following intrusive force after 3 days and 3 weeks. 3. The lack of significant difference between extrusive and intrusive forces is most probably due to application of light forces.

\section{Acknowledgments}

This study was supported by a grant from the Vice Chancellor of Research of Mashhad University of Medical Sciences with grant number 85283 .

\section{References}

1. Cohen S, Hargreaves KM (2006) Pathways of the pulp. 9th ed, Mosby, St Louis, 460-533.

2. Barwick PJ, Ramsay DS (1996) Effect of brief intrusive force on human pulpal blood flow. Am J Orthod Dentofacial Orthop 110, 273-279.

3. Anstendig HS, Kronman JH (1972) A histological study of pulpal reaction to orthodontic tooth movement in dogs. Angle Orthod 42, 50-55.

4. Guevara MJ, McClugage SG Jr (1980) Effects of intrusive forces upon the microvasculature of the dental pulp. Angle Orthod 50, 129-134.

5. Vandevska-Radunovic V, Kristiansen AB, Heyeraas KJ, Kvinnsland S (1994) Changes in blood circulation in teeth and supporting tissues incident to experimental tooth movement. Eur J Orthod 16, 361-369.

6. McDonald F, Pitt Ford TR (1994) Blood flow changes in permanent maxillary canines during retraction. Eur J Orthod 16, 1-9.

7. Wong VS, Freer TJ, Joseph BK, Daley TJ (1999) Tooth movement and vascularity of the dental pulp: a pilot study. Aust Orthod J 15, 246-250.

8. Stenvik A, Mjör I (1970) Pulp and dentin reactions to experimental tooth intrusion: a histologic study of the initial changes. Am J Orthod 57, 370-385.

9. Mostafa Y, Iskandar KG, EI-Mangoury NH (1991) Iatrogenic pulpal reactions to orthodontic extrusion. Am J Orthod Dentofac Orthop 99, 30-34.

10. Raiden G, Missana L, Santamaria de Torres E, Kozuszkos S, Pedroso R (1998) Pulpal response to intrusive orthodontic forces. Acta Odontol Latinoam 11, 49-54.

11. Konno Y, Daimaruya T, Iikubo M, Kanzaki R, Takahashi I, Sugawara J, Sasano T (2007) Morphologic and hemodynamic analysis of dental pulp in dogs after molar intrusion with the skeletal anchorage system. Am J Orthod Dentofacial Orthop 132, 199-207.

12. Brodin P, Linge L, Aars H (1996) Instant assessment of pulpal blood flow after orthodontic force application. J Orofac Orthop 57, 306-309.

13. Grünheid T, Morbach BA, Zentner A (2007) Pulpal cellular reactions to experimental tooth movement in rats. Oral Surg Oral Med Oral Pathol Oral Radiol Endod 104, 434-441.

14. Kumar V, Abbas AK, Fausto N (2005) Robbins and Cotran pathologic basis of disease. 7th ed, Elsevier Saunders, Philadelphia, 5-116.

15. Proffit WR, Fields HW, Sarver DM (2007) Contemporary othodontics. 4th ed, Mosby, St Louis, 94, 331-348.

16. Woodside DG, Berger JL, Hanson GH (2005) Selfligation orthodontics with the speed appliance. In: Orthodontics: current principles and techniques. 4th ed, Graber TM, Vanarsdall RL, Vig KW eds, Mosby, St Louis, 731.

17. Subay RK, Kaya H, Subay A, Tarim B, Cox CF (2001) Response of human pulpal tissue to orthodontic extrusive applications. J Endod 27, 508511.

18. Nanci A (2008) Ten Cate's oral histology: development, structure and function. 7th ed, Mosby, St Louis, 236-237. 